https://doi.org/10.32735/S0718-220120180004700167

105-120

\title{
LA "FUERZA DE LOS HUMILDES": MEMORIA E HISTORIA DE OTRA COLOMBIA EN VIVAN LOS COMPAÑEROS
}

The "strength of the humbles": memory and history of another Colombia in Vivan los compañeros

\author{
ANTONIO BECERRA BOLAÑOS \\ Universidad de Las Palmas de Gran Canaria (España) \\ antonio.becerra@ulpgc.es \\ NAYRA PÉREZ HERNÁNDEZ \\ Universidad de las Américas-Quito (Ecuador) \\ nayra.perez@udla.edu.ec
}

\section{Resumen}

Aunque Carlos Arturo Truque (1927-1970) sigue siendo poco conocido, no podemos hablar de literatura afrocolombiana, ni colombiana, sin su aporte. Con una producción literaria dispersa en publicaciones periódicas, el chocoano apuesta por el cuento cuando este no era suficientemente valorado en su país. Vivan los compañeros recoge todos sus cuentos (25), en los que se acerca tanto a los personajes excluidos de la sociedad como a los episodios de la historia colombiana más "vergonzosos", desde un lenguaje que se aleja de todo academicismo. Su obra, calificada en la época de "literatura sucia", y ubicada concretamente en el Chocó y el puerto de Buenaventura, no es ajena a cualquier injusticia humana. Además, la necesidad de Truque de plasmar el habla de su comunidad no le impide contemplar las nuevas técnicas narrativas que llegaban entonces de Norteamérica. Así, renueva el cuento colombiano desde el plano formal y de contenido.

Palabras clave: Literatura afrocolombiana; cuento contemporáneo; literatura de la violencia; memoria e historia; lenguaje e identidad.

Abstract

Although Carlos Arturo Truque (1927-1970) is still not well known, we cannot talk about Afro-Colombian, or Colombian literature, without mentioning his contribution. With an unfocused literary production in periodic publications, the "chocoano" bets on the short story when this genre was not highly valued in his country. Vivan los compañeros collects all his short stories (25), where he approaches the excluded characters of society as well as the more "shameful" episodes of Colombian history, from a language that distances itself from all academic art. His work, described at the time as "dirty literature" and specifically located in Chocó and the port of Buenaventura, is not alien to any human injustice. Besides, the need for Truque to express the speech of his community does not prevent him from contemplating new narrative techniques coming from North America. Thus, he renews the Colombian short story from the formal level and its content.

Key words: Afro-colombian literature; contemporary tale; La Violencia Literature; memory and history; language and identity. 


\section{INTRODUCCIÓN}

Hay escritores que, a pesar de no contar con una amplia obra, pasan a la historia por su personalísima voz. Este es el caso de Carlos Arturo Truque (1927-1970), cuyo primer libro, Granizada y otros cuentos (1953), fue incluido entre las cien mejores obras literarias de Colombia del siglo XX por la revista Semana. A pesar de que "el aliento partidista y la preferencia ideológica del autor se dejan ver en el volumen", la publicación destacaba "su valor documental, terrible testimonio de su época" (Semana). La mención de aquel libro, publicado cuatro décadas antes, apunta hacia una obra que refleja las duras condiciones de los desposeídos, pero va más allá de ese carácter documental.

Salvador Bueno incluirá uno de sus textos, "Sonatina para dos tambores", en la antología de cuentos negristas publicada en la Biblioteca Ayacucho, editorial conocida por su vocación latinoamericana. Llama, sin embargo, poderosamente la atención que el antólogo cubano seleccione solo a tres autores colombianos, cuando Colombia es uno de los países con mayor población afro de América Latina (Ecuador, por ejemplo, aparece representada por cinco autores y Perú, por seis). Si bien no la justifica ${ }^{1}$, Bueno ofrece indirectamente una explicación al porqué de esa menguada selección: gran parte de los escritores colombianos "dedica más atención a la composición de novelas que a la de cuentos" (XXII), por lo que se podría inferir que el corpus que había manejado el antólogo era limitado ${ }^{2}$. Ello sería reflejo del deficiente desarrollo sociocultural de la comunidad afrocolombiana, como plasma la obra de Truque, consecuencia de un contexto en el que la población negra carecía de un estatus propio hasta la Constitución de 1991, sepultada bajo el engañoso manto del mestizaje (Cunin, 2003).

Si bien se puede hablar de cierta presencia de Truque en un canon de la literatura colombiana, aunque sea parcial $^{3}$, múltiples circunstancias han contribuido al relativo desconocimiento de su obra, su figura y su significado, tanto nacional como internacionalmente, siempre, como se puede observar en el juicio de Semana o en el silencio de Bueno, contemplado bajo cierta sospecha ideológica o literaria.

\footnotetext{
${ }^{1}$ En la primitiva antología aparecía un cuento de Arnoldo Palacios, pero finalmente no pudieron contar con el permiso para su publicación.

${ }^{2}$ Sin querer entrar en juicios de valor, creemos que Bueno no consideraba o no conocía demasiado a los escritores colombianos: dedica unas líneas al "esforzado escritor" (XXIII) Manuel Zapata Olivella y a Umberto Valverde. Prescott (1999) había ofrecido una nómina que podría aparecer en una antología de cuentistas: "Una seleccion de cuentos incluiría a maestros como José Francisco Socarris, Carlos Arturo Truque, los hermanos Antonio, Manuel y Juan Zapata Olivella y varios escritores de las nuevas generaciones del Chocó" (p. 560).

${ }^{3}$ Hay que recordar que la primera edición de Vivan los compañeros aparece en la colección Clásicos Regionales de la Universidad del Valle en 2004. Muñoz Loaiza considera la introducción en el plan lector de los centros colombianos de enseñanza, dentro de la Cátedra de Estudios Afrocolombianos (CEA), de "la lectura de Cantos populares de mi tierra del maestro Candelario Obeso, de Cuentos para dormir a Isabella [...], de Vivan los compañeros de Carlos Truque, o quizá No give up Maan de Lenito Robinson (todas publicadas por el Ministerio de Cultura dentro de su colección Biblioteca de Literatura Afrocolombiana)" (C. Truque, 2010, p. 115).
} 
La producción literaria de Truque no es, en modo alguno, extensa y ha ido formándose por aglomeración hasta conformar el volumen Vivan los compañeros (2004, 2010), que reúne todos los cuentos que escribiera en su corta vida. Fue distinguido en diversas ocasiones, entre otras, con el Premio Espiral por su libro Granizada y otros cuentos (1953); el Premio del Festival de Berlín por su única pieza teatral, Hay que vivir en paz (1951), y con el Tercer Premio de la Asociación de Escritores y Artistas de Colombia por "Vivan los compañeros", certamen que significará el primer reconocimiento a Gabriel García Márquez y la primera publicación del futuro Premio Nobel, junto con Guillermo Ruiz Rivas y el propio Truque (1954) y reeditado recientemente en edición facsimilar (Mattos, 2014).

Truque quiso dejar constancia de sus circunstancias literarias en "La vocación y el medio. Historia de un escritor" ${ }^{\prime 4}$. En esta poética, escribe respecto de su toma de conciencia por acontecimientos que le harán desarrollar la misma actitud vital y literaria de su gran amigo Manuel Zapata Olivella. Para ambos ética, postura política y palabra irán siempre solidariamente unidas. Esta es una actitud compartida en la región sudamericana por muchos otros escritores, como los del Grupo de Guayaquil, cuya influencia se hará sentir en la obra de Truque.

Más de cuatro décadas después de la muerte del cuentista colombiano (su figura recibió distintos homenajes en el $60^{\circ}$ aniversario de su natalicio), la crítica que lo ha trabajado, tanto en Colombia como fuera de ella, en especial en Estados Unidos ${ }^{5}$, coincide en destacar a Truque como uno de los pioneros del cuento moderno en su país, "una de las pocas [obras] de la narrativa colombiana que ha captado la realidad con poderosa fuerza descriptiva y asombrosa fidelidad en la exaltación de las pasiones humanas dentro de un modo implacable y desgarrado" (Díaz Granados, 1987, p. 9).

Sandino Velázquez señalaba como "probables signos" de la marginación de Truque "su condición de negro cuarterón, como Puskin (abuelo blanco, abuela blanca, padre blanco, madre negra) y su condición de escritor social implacable" (Sandino, 1987, pp. 19-20). Creemos que el gran "problema" es la complejidad de su obra, debido a la imposibilidad de catalogarla bajo una única etiqueta. La riqueza de la obra de Truque está precisamente en las múltiples teclas que toca, no solo por los variados temas que aborda (por lo que su obra va más allá de poder ser catalogada de narrativa de la violencia, de cuentística negrista, narrativa criollista o realismo social), sino por su postura innovadora, también, de la forma, como ya veremos; pero siempre, de ahí la elección del título de nuestro artículo, bajo la brújula de su "fe profunda en la fuerza de los humildes" (C. Truque, 2010, p. 43).

\footnotetext{
${ }^{4}$ Este texto apareció publicado en la revista Mito en 1955 y en las dos ediciones de Vivan los compañeros (2004, 2010).

${ }^{5}$ Afro-Hispanic Review aborda su obra completa de manera global en el volumen VI. Martínez cuenta que Truque envió dos de los ejemplares de su corta edición de Granizada al exterior, una de las cuales cayó en manos de quien sería editor de la revista, Stanley A. Cyrus.
} 
El objetivo principal que nos proponemos es abordar algunas de esas circunstancias de las que hablábamos al principio, que son ciertamente "sombras", pero terminan alumbrando su obra: la elección del cuento como género privilegiado y su innovación formal; la violencia y las dificultades sociales que atraviesan su vida y obra; y la conciencia afrodescendiente y su visibilización desde dentro del lenguaje.

\section{EL CUENTO COMO GÉNERO}

$\mathrm{Al}$ analizar el panorama del cuento negrista, Bueno apunta una característica que no debemos soslayar. Muchas de las piezas literarias que aparecen en su antología se encuentran enmarcadas en la cuentística, si bien algunas de ellas podrían ser consideradas "como meros relatos, estampas o viñetas narrativas" (IX). Con ello Bueno parece subrayar la necesidad de estos autores de fijar en la memoria, de manera breve, tipos o costumbres, desatendiendo, de alguna manera, la parte narrativa en aras de la fuerza testimonial del relato, como un instrumento de reivindicación o, si se quiere, de visibilización social/cultural.

Una de las explicaciones de la preferencia del cuento por Truque puede ser de índole práctica. Truque escribirá en periódicos y revistas -muchas veces sin poder firmar por la situación política del momento- comentarios de libros, biografías breves y hasta poemas, además de ejercer como traductor y escritor de libretos para televisión, por lo que estaría habituado a lo breve, donde se encontraría más a gusto. A ello habría de sumarse otra más estética: la vocación de Truque por "lo otro" atraviesa también su planteamiento formal desde la misma elección de un género literario poco considerado en su época en Colombia. Él mismo lo cuenta en una entrevista a Álvarez d'Orsonville, recogida en su libro Colombia literaria (1960):

El género cuento no ha tenido en nuestro país el cultivo necesario. Una modalidad tan exigente impone ciertas cualidades de observación psicológica y capacidad de síntesis que no todos poseen. La demasiada afición de nuestros literatos por la poesía ha ayudado a que el cuento, la novela y el ensayo, para no decir nada del teatro, se hayan quedado sin recibir el impulso deseable (citado en S. Truque, 2010, p. 17).

En aquellos años el cuento en Colombia, cuyo cultivo se produce en todas las épocas desde la Colonia, no poseía una tradición o línea de continuidad; su presencia, más bien, en la producción narrativa de los autores era marginal, ya que era considerado un género menor, como una especie de entrenamiento. Esta escasa importancia se ve reflejada también en el espacio que tuvo en las antologías e historias de la literatura colombiana o en el rigor de sus estudios frente a otras manifestaciones literarias (Berrío Moncada). Hasta 1952 no existió ningún intento de sistematización y únicamente después de los años sesenta (1963) adquiere un papel más relevante para los historiadores de la literatura (Barón Gil). Es precisamente en los cincuenta cuando, según Vélez, el cuento y la literatura colombianos experimentan una transformación en 
la que Truque participa, al plantear nuevas formas frente al pintoresquismo tradicional imperante.

El cuento, para Truque, "es solo la descripción exhaustiva de un momento vital" (p. 18), en donde tienen cabida las "preocupaciones y problemas del hombre y de su época" (p. 19). Por eso, como considera Benita Clarke, podría ubicarse el estilo de Truque "bajo la rúbrica del neorrealismo" (p. 11), el que aún no se habría agotado en Hispanoamérica. La realidad, para Truque, queda regada por el "toque genial de los creadores para diferenciarlos de las crónicas más o menos reales, pero intrascendentes" (p. 19), como le explica a Álvarez d'Orsonville ${ }^{6}$.

En sus inicios, Truque acoge las técnicas en especial de los narradores norteamericanos, "desde los fabulosos relatos del gran patriarca Mark Twain, pasando por O'Henry, el mismo Faulkner y Hemingway -de quien heredó el buen uso de la frase corta y los diálogos magistralmente elaborados" (Martínez, 1987, p. 11). Como ocurre con García Márquez, Truque hará uso de las técnicas, pero los temas serán "autóctonos", término que englobaría hasta lo más vergonzoso de la realidad colombiana, como sostiene Díaz Granados, y "aun en las más difíciles circunstancias vitales [...] fue un escritor que asumió su destino con absoluta devoción" (p. 10).

La renovación formal que emprende Truque viene a dar más fuerza a la actitud renovadora que mantiene en el plano del contenido; se dan la mano:

Porque para llegar a la universalidad hay que partir de los elementos que se tienen a mano y laborar con ellos para situarlos en planos elevados de la creación. Lo contrario, el sometimiento irrestricto a las culturas foráneas, solo puede dar por resultado el arte imitativo, sin base de sustentación y sin valor alguno (C. Truque, p. 43).

Truque evidencia su gusto por formas literarias simples, porque las considera efectivas, de acuerdo con una tradición cuyas formas son conocidas. En este sentido, y como comentábamos, hace uso de formas menores (y breves) del cuento: desde la estampa o la viñeta ("Las gafas oscuras", "De cómo Jim llegó a olvidar") hasta la fábula ("La aventura de Tío Conejo"), para llegar al cuento, como el que da nombre al volumen, "Vivan los compañeros". Todas estas formas son percibidas por los lectores como propias, como pertenecientes a una tradición literaria conocida por los miembros de la comunidad.

\section{MEMORIA HISTÓRICA Y COMUNIDAD}

En uno de los capítulos de Triste fim de Policarpo Quaresma, de Lima Barreto (1911), el mayor acompaña al general Albernaz en su visita a una anciana negra que servía a su familia para que le recuerde algunas canciones "do tempo do cativeiro"

\footnotetext{
6 "Gorki nos dio una visión exacta del alma rusa, el modo de ser del campesino, del vagabundo, de la prostituta. No temió decir nada, por vulgar que fuera, pues entendió que todo tiene su belleza y que el pecado y los vicios que tanto espantan a los moralistas, son parte de la naturaleza humana. El caso vuelve a repetirse en Estados Unidos cuando la Gran Crisis" (en S. Truque, 2010, p. 9).
} 
(Lima, 1997, p. 31) que quiere usar en una fiesta. La nieta de la anciana le responde que las ha olvidado. Tras ser requerida nuevamente por el general, la anciana le canta una canción de cuna ante el desencanto de los visitantes. Quaresma se interroga: "Como é que o povo não guardava as tradições de trinta anos passados? Com que rapidez morriam assim na sua lembrança os seus folgares e as suas canções?” (p. 32).

La escena, narrada por el mestizo Lima Barreto, tiene una lectura literal, la del olvido de las tradiciones por parte de la comunidad afro, simbolizada en la anciana. Esta ha sido incapaz de transmitir su memoria. Sin embargo, el hecho de que sea la nieta quien responda por su abuela apunta a que sí ha transmitido aquellas canciones (ella las conoce), pero no las quiere recordar para el fin que los otros quieren destinarlas, por tanto, podría recordarlas, pero se niega a que pierdan su "verdad" (el contexto en el que tiene sentido dicha tradición). Se puede entender este olvido, por tanto, como una resistencia a las mediaciones que otros quieren hacer de esa memoria.

Truque subraya en su poética memoria y verdad. Escribir acerca de sí mismo es escribir de su comunidad, impelido por una obligación moral para con los suyos, cuyas circunstancias no son conocidas por nadie, y que forman parte de una verdad:

Lo único que podría garantizar es que este testimonio lo he vivido y que antes que yo lo vivieron otros, de los cuales no se conserva memoria. Por ellos doy a ustedes un poco de sus vidas y mucho de la mía (p. 36).

Cuestionado por Álvarez d'Orsonville, el escritor colombiano no considera lo social como una opción en la literatura; los planteamientos sociales "existen independientemente de ese deseo. Están allí, no pueden ser negados" (S. Truque, 2010, p. 18). Solo desde el punto de vista de la temática que abordan, más del $75 \%$ de sus cuentos se centran en aspectos que pueden ser considerados "sociales": la guerra, la violencia, la injusticia social o el racismo.

Tampoco es casualidad el título que dio a su poética, "La vocación y el medio. Historia de un escritor", de indudable resonancia orteguiana ${ }^{7}$. Su planteamiento coincide con la postura de Zapata Olivella, para quien:

...el autor se da y se debe a un fenómeno histórico. Su obra no es un simple rapto de inspiración, sino que incluye, además, una forma de existir, una posición ante la realidad social e individual, consciente e inconsciente a la vez. Analizar este sentir del escritor como individuo viviente, y el contenido de su obra como proyección en esa realidad, constituye, debe constituir, el objeto de la crítica

\footnotetext{
7 En su "Breve panorama de la literatura de ficción en el Ecuador contemporáneo" (1957), Pareja Diezcanseco (2010) comienza con estas palabras su análisis del Grupo de Cuayaquil, al que pertenecía: "Vengo otra vez por el calendario. Y por la antipática, en cierto modo, explicación de la obra de arte por la realidad circundante. Después de todo, no marxistamente, pero así muy a lo Ortega y Gasset, el hombre afirma su propia capacidad cuando comprende mejor su circunstancia, cuando es mejor espectador de sí y de las cosas, variable posición no exenta, desde luego, de riesgos, si es que la variedad del acontecimiento no es reducida a una unidad de superior comprensión" (p. 73).
} 
literaria. Solo así podría crearse un terreno que permita no solo la comprensión del autor-obra, sino testimoniar su aporte a la sociedad (p. 237).

Para Sandino Velázquez (1987), "el hecho social es la razón de su existencia como escritor. Dueño de una profunda sensibilidad y de un claro conocimiento de su realidad, supo plasmar en sus cuentos una imagen dolorida y franca del hombre colombiano" (p. 19). Cyrus señala que muchos autores hispanos, entre ellos el propio Truque, habían revelado una tendencia por parte de las elites, los editores y los críticos de no promover obras que reflejaran experiencias de los negros. La toma de conciencia de su escritura surge, como el propio Truque señala, en un entramado literario dominante totalmente escapista: "Para quienes quieran una forma artística, nutrida de las condiciones de vida de la masa del pueblo colombiano, el camino está vedado" (C. Truque, 2010, p. 40).

De modo parecido se expresa Zapata Olivella, quien había apostado también por el mismo camino, respecto de la realidad literaria de Colombia, extrapolable a la latinoamericana, que daba la espalda a los temas "autóctonos" de manera general:

La conspiración de los antinacionalistas también se extiende a la novela. Últimamente han aparecido dos tendencias, igualmente funestas, que atentan contra el normal desarrollo de nuestra literatura. El tradicionalismo apegado a una retórica anacrónica que más se ocupa de la gramática que del fenómeno psicológico y conceptual de la novela contemporánea. Y el cosmopolitismo -léase universo sin frontera que tiene por patria las grandes cosmópolis- que pretende desconocer la realidad para trazar a su antojo las normas estéticas derivadas de apresuradas lecturas foráneas (Zapata, 2010, pp. 201-202).

Precisamente a ese alejamiento de la realidad social por parte de los escritores atribuye Truque la falta de lectores: "La gente no quiere leer", decía. Y no quiere leer porque no comprende; porque no se ve reflejada en la obra" (pp. 41-42). En cuentos como "Vivan los compañeros", "Sangre en El Llano", "José Dolores arregla un asunto" o "La diana", Truque va a abordar el tema de la violencia y la guerra. Simplemente, nuestro autor no puede ignorar una realidad que estaba viviendo su país, que le salpica también en lo personal mediante, por ejemplo, la censura, y de una dureza extraordinaria, a juicio de Howsbawn:

La dimensión del periodo llamado la violencia que oscila entre finales de los años cuarenta y mediados de los sesenta, ha sido considerado por algunos analistas el enfrentamiento armado más intenso de América Latina en el siglo XX después de la guerra civil mexicana y de corte rural y no urbano, exceptuando espacios como los departamentos del Valle y Caldas (citado por Galindo Cardona, 2007, p. 132).

El tratamiento del tema lo hará desde distintas perspectivas, ya que la misma violencia se presenta poliédricamente, es decir, y en palabras de Galindo Cardona (2007): "La intensidad y las características de la violencia no fueron iguales en toda 
Colombia" (p. 132); pero, además, está enraizada en la sociedad y en la historia colombianas, como escribía Zapata Olivella (2010):

Si nosotros entendemos la violencia política en 1948 y en la década que lo continúa como un fenómeno aislado de la violencia que ha gestado toda la cultura colombiana desde el momento en que llegó el conquistador hasta nuestros días, y que el novelista no tiene esa visión del contexto histórico, es factible que su obra aparezca como un simple relato anecdótico de una situación parcial, y creo que esto es precisamente lo que está aconteciendo en muchas de nuestras obras (p. 340).

Truque no será el primero, ni el último, en formar parte de esa corriente literaria colombiana del siglo XX a la que se llamó "Literatura de la violencia". Autores como Daniel Casado con su Viento seco (1953); Álvarez Gardanzábal con Cóndores no entierran todos los días (1971) o Gabriel García Márquez con La mala hora (1962) y Cien años de soledad (1967), conformarían una nómina que aún hoy no se da por cerrada. Rodríguez Ruiz (2005) analiza tres tipos de violencia por medio de tres personajes abyectos: "el "pájaro" (asesino de la llamada "violencia" de los años cincuenta), el guerrillero (y su versión "rústica": el bandolero) y el "sicario" (130), en la novela de Gardanzábal, en Las muertes de Tirofijo (1972), de Arturo Alape, y La virgen de los sicarios (1994), de Fernando Vallejo, respectivamente. La conclusión a la que llega es que, si bien "el tipo de violencia, los modus operandi son distintos [...] el efecto es el mismo: la muerte se vuelve una constante" (p. 152).

Para Fabio Martínez (2004) no sería adecuado catalogar la obra de Truque en la corriente de la denominada literatura de la violencia. Se trata de una temática que obsesionará a muchos autores e, indudablemente, "Vivan los compañeros" se inscribiría dentro de ella, además de que nos ofrece al "escritor maduro, con un tono y una voz propia y depurada, como se verá cuatro años más tarde con "Sonatina para dos tambores" (p. 112). No obstante, en otros cuentos, como "La noche de san Silvestre", "Lo triste de vivir así", "Porque así era la gente" o "El día que terminó el verano", la temática que abordará será la de la injusticia social, esto es, "la vida de los oprimidos y explotados del campo y de la sociedad", como señala Morales Aguilar, donde va a encontrar las raíces de su estética, lo que le exigirá "romper con el lenguaje que en el país se tenía por literario en su momento" (p. 15). Esa desigualdad la conoce y la recrea en su mismo lugar de nacimiento: el Chocó, suerte de Macondo ${ }^{8}$ que Truque (2010) describe de esta manera:

Nací en la era mecánica, en un pueblo que la desconocía. Cualquier pueblo de Colombia, de esos que se quedan en un remanso de la civilización y que conservan como tesoro más preciado lo elemental en la existencia. Hasta mis

\footnotetext{
8 "Paradójicamente rica y miserable a la vez; olvidada y menospreciada por el Estado y por los gobiernos pese a sus riquezas, pero por ello mismo expoliada y saqueada por extranjeros ávidos de riqueza" (Morales Aguiar p. 14).
} 
ocho años no conocí la barrera que separaba a unos seres de otros. Como el pueblo era pobre, nadie pensó nunca que la riqueza era un factor para brillar y valer más que los que no la poseían. Siendo un pueblo de negros, nadie imaginó que las diferencias de pigmentación pudieran abrir abismos insalvables y ser usadas para establecer la dominación y el repudio sobre quienes se consideraron inferiores (p. 40).

Esta región de la infancia, con sus luces y sombras, saltará a sus páginas en cuentos como "Granizada", donde expone, escribe Panchón Padilla (1987), "la música del Chocó, que [...] tiene un gran ancestro africano, esa manera de ser del hombre chocoano, de vivir el diario, lo cotidiano, sin pensar en el mañana" (17). Truque escoge un camino que considera que no ha sido emprendido por nadie con anterioridad, consciente de la relevancia de su labor como escritor y, sobre todo, como portavoz de una comunidad que tiene mucho en común con otras comunidades del país ${ }^{9}$. Pionero en las letras colombianas, como señala Sandino Velázquez, sostiene una postura estética que se sitúa en las antípodas del "mundillo literario capitalino" (Truque, 2010, p. 41):

El hombre frente a su historia, frente a su condición, sumergido en una realidad atroz y alienante con todas las taras que el coloniaje aporta en todos estos siglos de sometimiento es tema muy reciente en nuestras letras y con Carlos Arturo Truque muy posiblemente logra primera plena coherencia (excepción hecha de $L a$ vorágine, la novela costumbrista, etc.) (p. 20).

\section{EL LENGUAJE: HACIA LA NORMALIDAD NACIONAL}

La manera en que los textos literarios transmiten el habla de una comunidad "periférica" refleja la consideración que esta tiene de su propia cultura. Así, la incorporación del léxico y de los giros gramaticales propios sin intención paródica y sin ser reflejados, y por tanto entendidos, como deturpación del idioma es el primer paso del proceso de visibilización de una comunidad. Truque plantea una renovación precisamente desde el mismo lenguaje en que se expresan sus personajes, que es el "vernacular, de giros y expresiones utilizados por el pueblo para reflejar el mundo y su mundo", como lo caracteriza Morales Aguilar (1987):

Es un lenguaje musculoso, lleno de vida, que aún hoy se mantiene con un verdor que asombra. Y no cae en localismos ni regionalismos intraducibles, sino que logra, a través del manejo de la polisignificación del lenguaje mismo, hacerlo comprensivo contextualmente, connotativamente. Truque es un pionero en el país en el tratamiento de lo popular sin los lentes del costumbrismo tan propio de nuestra literatura del siglo XVIII y XIX (p. 15).

\footnotetext{
9 "Creo que tengo la suficiente autoridad para hablar de problemas que he sufrido en carne viva; es más, creo que los hombres que se inician y trabajan por hacer una gran obra que enorgullezca las letras patrias, me comprenden. Ninguno de ellos ha podido librarse del hambre, del sufrimiento, de la incomprensión de los dómines, de las críticas del clan, de la mirada sardónica de los reyezuelos de redacción y de los gritos de espanto de las viejas beatas que se han apoderado de la cultura nacional" (p. 42).
} 
Es, en primer lugar, un lenguaje con el que el pueblo puede sentirse identificado, de la misma manera que los temas que trata su literatura. Truque actuaría como el historiador en el sentido que lo plantea Hayden White. Para White, la forma en que la historia es transmitida está definida por la propia escritura; con ello, señala que la comprensión ${ }^{10}$ del hecho histórico por parte del lector se produce porque aquel está familiarizado con cómo aparece el relato histórico y está contado, ya que difícilmente comprenderá los hechos que se le presentan sin que estos hayan sufrido un proceso de depuración estilística. Es este el pensamiento de Zapata Olivella, para quien, frente al habla oficial, impuesto y heredado, hay otra habla nacida "en el ajetreo cotidiano del pueblo", compuesta por:

Palabras que nadie sabe quién las inventó, de dónde vienen, hacia dónde van en el continente o en qué sitio se quedan, fuera o dentro de los cartabones académicos. Son millares. Unas viven un día y otras perduran. Las creamos inconscientemente $\mathrm{y}$, sin embargo, comunican un concepto que es captado de inmediato por el que oye, habitante del mismo lugar, de la geografía social que nos enfrenta. Cuando dudo acerca de estos vocablos y expresiones, no puedo recurrir al diccionario que los ignora, sino al padre, al tío, al abuelo. Si me las confirman como elementos vivos, conocidos por ellos, las incorporo a mi vocabulario (White, 2003, p. 218).

Indudablemente, y con algo de rezago respecto de otros países y comunidades ${ }^{11}$, Zapata Olivella, como en los textos de Truque, está planteando el problema del "idioma nacional", surgido de la evolución del español implantado por España por el mestizaje o el contacto con otras lenguas y que se planteará tímidamente en Hispanoamérica a partir de los procesos de independencia y con fuerza a fines del siglo XIX y principios del XX. Zapata Olivella (2010) concluye:

Es el nuevo idioma del mestizo, ya sin antecedentes semánticos, pero con una raíz nueva: la vida. Creo que con este idioma popular sucede en Hispanoamérica lo que con el latín vulgar: será el nuevo núcleo del habla regional del que nacerán troncos -lenguas romances se llamaron entonces- que constituirán los idiomas nacionales hispanoamericanos (p. 219).

\footnotetext{
10 “'Comprender es un proceso que consiste en hacer que lo no familiar, o lo 'extraño' en el sentido que Freud le da a ese término, aparezca como familiar; o trasladarlo del dominio de las cosas sentidas como 'exóticas' e inclasificadas a un cierto dominio de la experiencia codificada adecuadamente para ser sentida como humanamente útil, no amenazante o simplemente conocida por asociación" (p. 71).

11 "Unamuno fue atacado [en 1902] porque "no quiere que se hable una lengua dura y fiambre". Precisamente, es ese el planteamiento de Ricardo Palma (1901) cuando escribe a Galdós a propósito del afán impositor de la Academia Española y la necesidad de incluir nuevos vocablos provenientes de los países americanos: 'Capítulo de otra cosa, señor académico. Yo padezco de una chifladura, que se aumentó con mi concurrencia a las juntas de la Academia. En mi librito Recuerdos de España, del que también le mando hoy ejemplar, verá U. en resumen las peloteras que tuve con nuestros compañeros encaprichados en rechazar vocablos (y verbos principalmente) de que los americanos no podemos prescindir, ni debemos ni queremos" (Becerra Bolaños, 2013, p. 5).
} 
Pero ¿de qué pueblo recoge el habla Truque? Por supuesto, de manera especial, el dialecto afrocolombiano del Pacífico, donde nace y se cría, como vemos en los cuentos de temática del racismo y del mundo afro, como "Sonatina para dos tambores", "La aventura de tío Conejo", "Fucú" o el "El Pigüita" (C.A. Truque):

-iQué gol de mierda! Pigüita estaba de güevero.

-iAh! ¡Qué hijueputa Pigüa que no sirve pa'un culo! Salite de aquí - prorrumpió Bambocha encolerizado.

$[\ldots]$

- ¿Te sacaron? -le preguntó con voz ronca.

-Sí, el Bambocha ese. No me quiere. ¡Quesque osai! (p. 200).

Este es un modo de hablar muy peculiar, un "semicriollo afrohispánico" de acuerdo con Lipski, dialecto del Pacífico, según Suárez Reyes (2010):

...en el que sobresalen muchas especificidades desde los diferentes puntos de vista de la variación lingüística partiendo de las léxico-semánticas hasta las morfosintácticas y fonético-fonológicas entre otras que se reflejan en el carácter netamente marginal, rodeada por selva y mar que se escapan cada vez más para mostrar el español hablado en el Pacífico y se expresan desde allí para Colombia y el mundo (p. 2508).

Este logro, que hoy valoramos en Truque, y que dignifica y visibiliza la cultura de esta comunidad, le supuso en la época que su obra recibiera la etiqueta de "literatura sucia" (C.A. Truque), pues no escondía ningún aspecto de esa habla ni lo limaba de algún modo.

$\mathrm{Si}$, como ya vimos antes, para la estructura del género, nuestro autor mira y se deja influenciar por los autores norteamericanos, en el caso del tratamiento del lenguaje en su obra, como él mismo escribe en su poética, toma ejemplos más cercanos:

La enseñanza de los ecuatorianos y su vigorosa novela, conocida ya universalmente, es digna de ser seguida. Ese pequeño pueblo ha tenido el valor de presentar a la faz del mundo sus problemas sin avergonzarse por ello (p. 42).

Se refiere Truque al Grupo de Guayaquil, que vivió su esplendor creativo en los años 30, conformado por Joaquín Gallegos Lara, Demetrio Aguilera Malta (sus fundadores), José de la Cuadra, Enrique Gil Albert y Alfredo Pareja Diezcanseco. La fórmula de este grupo era "la realidad y nada más que la realidad", que lleva a todos los planos de la escritura: por un lado, en la temática de su obra, la vida del montubio, del indio y del obrero ecuatoriano, y, por otro, con un lenguaje que bebe del coloquio popular. Benjamín Carrión definirá la estética del Grupo como "el encuentro triunfal con la mala palabra, con el crudo decir popular, sin eufemismos ni iniciales pudibundas" (Bueno, 2003, p. XVII).

El decir de montubios, cholos e indios aparece en sus textos combinado con el discurso "artístico, de tal forma que su prosa resulta una perfecta simbiosis entre los niveles culto y popular, tanto en la expresión como en el contenido" (Ibáñez Ehrlich, 
1993, pp. 185-186). Los logros del Grupo de Guayaquil son producto de una tradición que se inicia a principios del siglo XX y que continuará, como señala Bueno, con autores como José de la Cuadra o el esmeraldeño Adalberto Ortiz y su novela Juyungo (1943). Pareja Diezcanseco (2010), al tratar la producción de estos años en Ecuador, emplea el epíteto "hornada febril" (p. 79), que dura unos 20 años y que ponen de relieve al "hombre personaje" de "un pueblo sin existencia cívica, bien dicho, con existencia subhumana". Ello supuso, además, una tendencia al maniqueísmo ("Blanco y negro, esqueleto y no carne de hombres"), aunque "el carácter sociológico, entiéndase bien, no significó una posición didáctica, pero sí una constante revolucionaria y una persistente denuncia de miserables condiciones de vida, y no disminuyó la calidad poética y artística" (p. 82).

Ese es el magisterio que sigue Truque. El cuentista colombiano concibe la denuncia solo a partir de la reconstrucción de momentos de la vida de sus personajes, a quienes da la voz. El diálogo cobra un papel relevante en la configuración de sus historias, como sucede en "Granizada", tal vez su mejor cuento y que lo vincula con la escritura de Juan Rulfo:

Recostó el cuerpo contra el horcón, dio una fumada fuerte al cigarrillo, con los ojos entrecerrados, y mirando el cielo meneó la cabeza con desencanto.

-¡Otra vez! ¡Maldita sea!

Luego medio inclinó la cara hacia la puerta del rancho para gritar:

-¡Eulalia...! ¡Eulalia...! Tráeme la ruana y decile al Bernardo que venga también.

Al rato oyose a la mujer gritando:

-¡Bernardo...! ¡Bernardo!

-¿Qué? -respondieron a la distancia.

-iQue venga...! ¿No está oyendo? (p. 57).

Truque se hermana en el dolor con sus personajes, pero no maquilla sus acciones, propias, en ocasiones, del egoísmo, la ignorancia o la falta de una educación. Ahí es donde hallan su propia dimensión humana. Santiago, el personaje de "Sonatina para dos tambores", quiere recordarle a Míster Stern que ha de llevar a su mujer en su lancha hasta Buenaventura para que le quiten el "ahoguido", y anda en la fiesta:

Pero lo de ir, no era para decirle nada. Era que sabía que allí andaba la Guillermina, de falda almidonada, los senos parados como dos cucuruchos. Lo que pasaba era que le iban subiendo unos deseos locos de ir a verse con ella para sentir el cosquilleo que sentía cuando las tetas grandotas le retemplaban al bailar la juga y el patacoré (p. 96).

Los personajes de Truque parten de una situación de desventaja frente al resto del mundo. Son héroes, porque tratan de rebelarse contra su destino, y creen que pueden sustraerse de su realidad; sin embargo, ello no sucede y los hechos acaban imponiéndose. Santiago o el Pigüita oscilan entre la realidad y el deseo; su ensoñación es del todo ilusoria. Así, el mundo en el que los personajes viven, sueñan y mueren está destinado a perpetuar dos realidades: la de los de arriba (Míster Wilson o Bambocha) y la de los de 
abajo (Santiago y el Pigüita). Este mundo, sin embargo, no se presenta de manera uniforme, pero sí responde a un ambiente que todos comparten.

\section{5. ¿CARLOS ARTURO TRUQUE, AUTOR AFROCOLOMBIANO?}

No podemos acabar este acercamiento a su obra sin hacernos esta pregunta, compleja, que intentaremos responder aun de manera breve por motivos de espacio. En primer lugar, hay que tener en cuenta de que, a pesar de que Colombia es el país con mayor población de ascendencia africana tras Brasil y Estados Unidos de América en el hemisferio occidental (Lawo-Sukam), hasta hace pocas décadas no existía una categoría de "literatura afrocolombiana" en su historiografía y su canon literarios. Prescott señala lo contradictorio del hecho de que escritores afrocolombianos como Obeso, Artel o Zapata Olivella sean conocidos nacional e internacionalmente, pero su eco se haya producido únicamente en sus regiones y comarcas, "sin que eso sea indicación del valor estético o cultural de su obra". De ellos, continúa Prescott (1999), pocos han sido considerados como "para figurar en antologías, historias y estudios críticos de literatura que se utilizan en las instituciones educativas y que efectivamente logran consagrar al autor y darle prestigio ante los ciudadanos de una nación" (p. 555).

Esto se debe, sin duda, a factores sociales, económicos y políticos que encuentran reflejo en el plano literario. Muchos de estos escritores, que en su mayoría carecen de recursos, se ven obligados a autoeditarse, lo que limita la circulación de sus obras y, por tanto, el reconocimiento y la inclusión en el acervo cultural del país, como apunta Lawo-Sukam.

La reproducción del habla del Chocó o el tratamiento en diversos cuentos del tema del racismo podrían ser considerados rasgos "afro" de la literatura de Truque, pero hay que señalar además que en una época en la que no existía conciencia ni el concepto mismo de Afro-Colombia. Como explica Valero, solo a partir de 1970 un grupo de investigadores estadounidenses comienza a mirar hacia las literaturas latinoamericanas "negras", a consecuencia de los movimientos por los derechos civiles de la población afro en este país.

Este grupo de autores, entre los que pueden destacarse por su significación a Richard Jackson y a Martin Lewis, trató por medio de sus estudios, de definir qué es aquello de "literatura afrocolombiana" vinculándola a conceptos como: “"orgullo' y 'solidaridad racial', asociados a su vez a la 'negritud' (blackness), entendida esta como la conciencia de un pasado y un presente caracterizados por el sufrimiento", para Jackson, y como el "background étnico", para Lewis, de acuerdo con Valero.

Sin desmerecer el valor que en su momento tuvieron estas primeras aproximaciones, más tarde se ha visto que habían sido casi un traslado de ideas del campo intelectual estadounidense a un contexto que difería mucho de aquel, tal vez por la peligrosa tendencia a universalizar "lo afro", cuando la cultura está hecha de prácticas y performatividades y no está determinada por un color. 
Además, profundizando un poco más, los autores afrocolombianos no tendrían la visión afrocéntrica ni eurofóbica de los escritores abanderados de la negritud, lo que es debido al mestizaje triétnico colombiano, que también podría llamarse transculturación en el sentido que para Cuba le da Fernando Ortiz. Su identidad, como señala Lawo-Sukam (2011), "no deriva de su aislamiento de la cultura europea sino de un proceso de integración étnico-racial y cultural" (p. 42) o, en palabras del ecuatoriano Adalberto Ortiz:

...de miscegenación étnica y cultural $[\ldots]$ no solamente en las manifestaciones somáticas del mestizaje, sino también en cierta corriente cultural, literaria y muy poderosamente en la música popular, en las creencias y supersticiones de los campesinos... De todos modos, la negritud nos ha restablecido la legitimidad de pertenecer a la cultura africana, al igual que somos parte también de la cultura hispanoamericana y la indoamericana (p. 96).

Así, desde este sincretismo cultural del que hablamos, la valoración de la identidad negra, más que por la etnia, pasa, a decir de Lawo-Sukam, por la "descripción, la denuncia y el anhelo de cambiar las duras condiciones de vida del afrocolombiano en una sociedad marcada por el racismo y la desigualdad social" (p. 49), lo que vemos clarísimamente en nuestro autor.

Truque, más que tomar la bandera de la negritud, agarra la de la injusticia social ${ }^{12}$, la de los oprimidos, ya que tenía muy claro que no se trataba de un problema "de pigmentación, sino que es un asunto político, es un asunto de la división de la sociedad en opresores y oprimidos, en explotadores y explotados" (Morales Aguilar, 1987, p. 15). Esta postura responde a una clara visión marxista de la realidad, aunque, por su amplio conocimiento de la vida de las comunidades afrocolombianas, en cuyo seno nació y de las que formó parte con todas sus consecuencias, toque aspectos negristas como el folclore, el habla, el racismo; pero desde una postura muy parecida a la del Nobel nigeriano Wole Soyinka: negro pero, como el tigre, sin necesidad de reclamar su tigritud/negritud. Más certero sería hablar de que Truque recuerda a los olvidados, que adquieren voz propia.

\section{BREVES CONCLUSIONES}

La obra de Truque y las reflexiones que hizo en su poética nos permiten acercarnos al otro/lo otro desde muchos ángulos. El escritor colombiano, contemporáneo de Gabriel García Márquez, compartió con él país y circunstancias; pero las realidades que crearon fueron completamente distintas, aunque siguieran similares estéticas.

Las memorias de Truque son una estilización de las memorias del Chocó; sus personajes compartieron con él la inocencia y la frustración, como consecuencia de ello nacería una conciencia que no se materializaría hasta décadas más tarde. Aun así, el decir

\footnotetext{
12 "Entre los infelices también hay diferencias profundas, que los humildes en ocasiones adoptan el mismo punto de vista de los poderosos y comienzan a levantar murallas entre ellos con la esperanza de tender un puente que los asimile a una clase social más alta" (p. 39).
} 
La "fuerza de los humildes": memoria e historia de otra Colombia en Vivan los compañeros

de Truque permaneció vivo por haber asimilado los elementos configuradores de un pueblo y por dominar el género por el que se decantó.

Para García Márquez (2000), en ocasiones el cuento es el germen de la novela, que puede ser la vida tal como la recordaba; para Truque el cuento es la vida tal como era. Truque no encontró la manera de hacer que la poesía abriera nuevas posibilidades a la historia, que relegaba a los otros al silencio, pero, al menos, les ofreció maneras de soñar un mundo que pudo imaginar mejor siempre y cuando estuviera en manos de los humildes.

\section{OBRAS CITADAS}

Barón Gil, Orlando (2014). El cuento colombiano y su presencia en las historias de la literatura nacional y las antologías del género. Disertación de tesis Universidad Nacional de Colombia, 2013. Web. 9 julio 2014.

Bueno, Salvador (2003). "Prólogo", Cuentos negristas. Caracas: Biblioteca Ayacucho.

Berrío Moncada, Maribel (2010). "El cuento colombiano: análisis de los criterios de selección en las historias y las antologías literarias", Estudios de Literatura Colombiana 26: 109-130.

Becerra Bolaños, Antonio (2013). "Una definición de lo americano en el epistolario de Benito Pérez Galdós". Actas del I Congreso internacional nuevos horizontes de Iberoamérica. Guaymallén: Qellqasqa.

Clarke, Benita (1990). "'La fuga' de Carlos Arturo Truque: El tema de la locura en una clave menor", Afro-Hispanic Review 9, 1/3: 11-17.

Cunin, Elizabeth (2003). Identidades a flor de piel. Bogotá: IFEA-ICANH-UniandesObservatorio del Caribe Colombiano.

Cyrus, Stanley A. (2002). "Ethnic Ambivalence and Afro-Hispanic Novelists", AfroHispanic Review 21, 1/2: 185-189.

Díaz Granados, José Luis (1987): “Carlos Arturo Truque: Un mundo implacable y desgarrado", Afro-Hispanic. Review 6, 3: 8-10.

Galindo Cardona, Yamid (2007). "El martirio agiganta a los hombres: Tres perspectivas artísticas de la violencia en el Valle del Cauca", Historia y espacio 29 (2007): 131-153.

García Márquez, Gabriel (2000). “Todo cuento es un cuento chino”. Cambio, 24 de julio: 80-82.

Ibáñez Ehrlich, María Teresa (1993). "Recursos estilísticos en las narraciones cortas del “Grupo de Guayaquil”, Anuario de estudios filológicos 16: 185-194.

Lawo-Sukam, Alain (2011). "(A)cercamiento al concepto de la negritud en la literatura afrocolombiana", Cincinnati Romance Review 30: 39-52.

Lima Barreto, Afonso (1997). Triste fim de Policarpo Quaresma, ed. Antonio Houassis y Carmem L. Negreiros. Madrid [...] Santiago de Chile: ALLCA XX.

Lipski, John (2004). "Las lenguas criollas de base hispana", Lexis XXVIII, 1-2: 461-508.

Martínez, Fabio (2004). "Carlos Arturo Truque: El Pacífico hecho ficción”, en Carlos A. Truque, Vivan los compañeros. Cali: Universidad del Valle. 
_ (1987). "En el sexagésimo aniversario de su nacimiento", Afro-Hispanic. Review 6, 3: 11-12.

Mattos Omar, Joaquín (2014). "Cuando García Márquez ganó su primer premio literario", Latitud, julio 2014.

Morales Aguilar, Álvaro (1987). "Las raíces de la estética de Carlos Arturo Truque A.", Afro-Hispanic. Review 6, 3: 13-16.

Muñoz Loaiza, Beydy (2012). "La cátedra de estudios afrocolombianos como elemento de inclusión en el currículo de la formación de formadores", Revista Papeles 4, 7: 110-115.

Ortiz, Adalberto (1975). "La negritud en la cultura latinoamericana y ecuatoriana", Revista de la Universidad Católica del Ecuador 7: 97-118.

Panchón Padilla, Eduardo (1987). "Carlos Arturo Truque en los premios literarios colombianos", Afro-Hispanic. Review 6, 3:17-18.

Pareja Diezcanseco, Alfredo (2010). Ensayos reunidos. Quito: Centro Cultural Benjamín Carrión.

Prescott, Laurence E. (1999). "Evaluando el pasado, forjando el futuro: Estado y necesidades de la literatura afrocolombiana", Revista Iberoamericana LXV núm. 188-189: 553-565.

Rodríguez Ruiz, Jaime (2005). "Pájaros, bandoleros y sicarios: Para una historia de la violencia en la narrativa colombiana (Un enfoque desde la Historia de las Mentalidades)", en Cecilia Castro Lee (comp.), En torno a la violencia en Colombia: una propuesta interdisciplinaria. Cali: Universidad del Valle.

Sandino Velázquez, Edgar (1987). "Lo social en la estética de Carlos Arturo Truque", Afro-Hispanic Review 6, 3: 19-21.

Semana (1999). "Los cien libros colombianos del siglo", 26 abril 1999.

Suárez, Felix (2010). "Etnoeducación: tradición oral y habla en el pacífico colombiano. 200 años de Iberoamérica (1810-2010)", Congreso Internacional: Actas del XIV Encuentro de Latinoamericanistas Españoles, Eduardo Rey Tristán y Patricia Calvo González (coord.) Santiago de Compostela: Universidad de Santiago de Compostela.

Truque, Carlos (2010). Vivan los compañeros, cuentos completos. Bogotá: Ministerio de Cultura de Colombia.

Truque, Sonia (2010). "Carlos Arturo Truque: Colombia a corazón abierto", en Carlos A. Truque: Vivan los compañeros, cuentos completos. Bogotá: Ministerio de Cultura de Colombia.

Valero, Silvia (2013). "¿De qué hablamos cuando hablamos de 'literatura afrocolombiana"? o los riesgos de las categorizaciones", Estudios de Literatura Colombiana, 32, enero-junio: 15-37.

White, Hayden (2003). El texto histórico como artefacto literario, introd ucción de Verónica Tozzi, Barcelona: Paidós, ICE y UAB.

Zapata Olivella, Manuel (2010). Por los senderos de sus ancestros. Textos escogidos: 1940-2000. Recopilación y prólogo de Alfonso Múnera. Bogotá: Ministerio de Cultura de Colombia. 